\title{
Impact of Regular Whole-Blood Donation on Body Iron Stores
}

\author{
Vijayram Reddy Ka, $K^{a}$ Shamee Shastry ${ }^{a, b} \quad$ Manish Raturic Poornima Baliga B ${ }^{a, b}$ \\ a Department of Immunohematology and Blood Transfusion, Kasturba Medical College, Manipal, India; \\ ${ }^{\mathrm{b}}$ Manipal Academy of Higher Education, Manipal, India; ' Swami Rama Himalayan University, Dehradun, India
}

\section{Keywords}

Blood donor · Iron deficiency · Serum ferritin · Anemia · Hemoglobin

\begin{abstract}
Background and Objectives: Regular and repeat blood donations may cause reduced body iron stores (BIS), which may lead to a shrinking donor pool. Furthermore, hemoglobin $\mathrm{Hb}$ itself is quite an inadequate measure to detect iron deficiency. Hence, our primary aim was to understand the effect of repeated blood donations on BIS in regular blood donors. Study Design and Setting: We conducted a prospective study on voluntary whole-blood donors (September 2015 through August 2017). Donor demographics were noted. Donors were further divided into four groups, depending on their number of donations. Their samples were tested for $\mathrm{Hb}$, red cell indices, and serum ferritin to check for reduced BIS. The data obtained were analyzed using SPSS version 20 (IBM, USA). Results: A total of 374 regular voluntary blood donors were included in the study. The mean serum ferritin levels in males and females were 75.4 and $36.2 \mu \mathrm{g} / \mathrm{L}$, respectively. There was a $45 \%$ decrement in the mean serum ferritin values in Group I (101.57 $\mu \mathrm{g} / \mathrm{L})$ in contrast to Group III (56.69 $\mu \mathrm{g} / \mathrm{L})(p<0.0032)$. In the study, $9.8,11.2$, and $4.8 \%$ of the donors were in Stage 1, Stage 2, and Stage 3 of reduced BIS, respectively. Of the donors, $11.2 \%$ were in Stage 2 of reduced BIS. Further donations in such cases can compromise donor safety. Conclusion: The present study demonstrates iron depletion in regular voluntary blood donors. In $11.2 \%$ of the donors, iron deficiency erythropoiesis was noted. A ferritin screening after the first donation followed up at the tenth
\end{abstract}

donation might help detect iron-deficient individuals. Iron supplementation for all regular blood donors and female donors in particular will help prevent the shrinking donor pool due to iron deficiency.

๑) 2019 S. Karger AG, Basel

\section{Introduction}

Regular donation may be one of the important causes of iron loss in blood donors. Bleeding results in movement of iron from body stores [1]. As iron storage reduces, its absorption increases subsequently. With frequent blood donation, an individual either reaches stability at a lower level of iron stores or becomes anemic. One $\mathrm{mL}$ of blood consists of $0.5 \mathrm{mg}$ of iron. Thus, a unit of blood (450 $\mathrm{mL}$ ) contains nearly $250 \mathrm{mg}$ of iron, representing about $30 \%$ of the average body iron stores (BIS) in males and nearly $80 \%$ in females [2]. Iron deficiency is often observed in long-term regular blood donors [3]. The frequency of blood donation has been so regulated as to prevent anemia in most donors, but quantitative information regarding the iron status of donors is still limited till date. Screening for hemoglobin concentration $(\mathrm{Hb})$ is a conventional part of the donor selection process, both in order to assure adequate quality of red cell concentrates collected and to safeguard the potential donor's health [4]. It is established that iron-deficiency anemia is the last stage in the pathogenesis of body iron depletion, and it is apparent that $\mathrm{Hb}$ levels by themselves are insufficient data for identifying blood donors with iron deficiency without anemia. Accurate diagnosis and detection of iron 
deficiency at an early phase require further laboratory testing with a high degree of accuracy and precision [3].

It has been predicted that donors deferred for low $\mathrm{Hb}$ donate relatively $30 \%$ less blood over the subsequent 4 -to5 -year period, even after their $\mathrm{Hb}$ normalizes in comparison to the donors who have not been deferred [5]. Considering donors deferred for low $\mathrm{Hb}$ constitutes a significant percentage of the total donor population. Understanding the prime causes for the deferrals and establishing an action plan to prevent them will help promote the blood donor well-being and improve the everdeclining donor pool. To accomplish the worldwide and nationwide drive to recruit and retain regular and repeat voluntary nonremunerated blood donors, the iron status of the donors must be diagnosed, and essential steps for iron supplementation should be taken [6]. To our knowledge, no standardized study has been conducted in the southern part of India to determine iron stores in blood donors. Considering all these reasons, and having a huge pool of repeat voluntary nonremunerated blood donors, we sought out to conduct this study. Our primary aim was to understand the effect of repeated blood donations on BIS in both male and female regular blood donors.

\section{Materials and Methods}

\section{Study Design}

A prospective study on voluntary whole-blood donors was performed after taking informed consent. Donors who attended the blood center attached to a 2,032 bedded tertiary care hospital in South India (Kasturba Hospital, Manipal, Karnataka) from September 2015 through August 2017 were reviewed. The study was approved by the institutional ethics committee prior to commencement (IEC-508/2015).

\section{Donor Selection Criteria}

Donors were asked specific questions about blood donation as per the donor questionnaire on the basis of the standards published in the technical manual of the Directorate General of Health Services [7]. All donors selected were asked the following questions: age at first donation, the total number of lifetime donations, number of donations within the previous year, the interval between donations, date of the last donation, dietary history, occupation, education, and consumption of iron supplements (if any).

\section{Inclusion Criteria}

The study included all regular voluntary donors who had donated, the last donation being within the previous year, and continued to donate regularly at least once per year [8]. The donors included in the study were further divided into the following four groups based on their number of donations: Group 1, donors who donated 1-10 times; Group II, donors who donated 11-20 times; Group III, donors who donated 21 times and above; and Group IV, regular donors deferred due to low $\mathrm{Hb}$.

\section{Exclusion Criteria}

All voluntary donors who did not fulfill the criteria of regular donors (lapsed donors) and those on iron supplementation were excluded from the study.

\section{Study Methodology}

A questionnaire was given to each donor after obtaining their informed consent for the participation in the study. Blood samples from the study subjects were collected for hematological tests such as $\mathrm{Hb}, \mathrm{MCV}$ (mean corpuscular volume), $\mathrm{MCH}$ (mean corpuscular $\mathrm{Hb}$ ), MCHC (mean corpuscular $\mathrm{Hb}$ concentration), and red cell distribution width (RDW). Red cell indices were measured by using KX-21 Sysmex (Coulter, Japan). Serum was transferred into plain vials and stored at $-20^{\circ} \mathrm{C}$ for the measurement of serum ferritin concentrations. Serum ferritin was estimated using ELISA (Calbiotech, USA) as per the manufacturer's instruction. Based on the body iron status, the donors were categorized under three stages: Stage 1, negative iron balance (reduced iron balance with a serum ferritin level between 15 and $30 \mu \mathrm{g} / \mathrm{L}$ ); Stage 2 , iron deficiency erythropoiesis with serum ferritin levels $<15$ $\mu \mathrm{g} / \mathrm{L}$ and normal $\mathrm{Hb}$; Stage 3, iron deficiency status with serum ferritin levels $<15 \mu \mathrm{g} / \mathrm{L}$ and microcytic hypochromic picture on the hemogram.

Donor demographics and data on the number of donations in the preceding 3 years were taken from blood bank software (Easy Software Solutions, Ahmedabad, India).

\section{Statistical Measurement}

The data were analyzed using SPSS version 20 (IBM, Chicago, IL, USA). The simple descriptive data (in a normal distribution) was analyzed through the mean with standard deviation, and quantitative data as percentages. The statistical analysis was done using Student's $t$ test. $p$ values $<0.05$ were considered statistically significant.

\section{Results}

A total of 374 voluntary blood donors were included in the study. The mean age was $33.5 \pm 7.63$ years (18-59). Based on the number of donations, Group I had 29\% ( $n=108)$, Group II had 27\% ( $n=101)$, Group III had 27\% $(n=100)$, and Group IV had $17 \%(n=65)$ donors as study subjects, respectively (Table 1 ). The male-to-female ratio was 4.7:1 (Table 2). Donor hematocrit (Hct), red cell indices (MCV, MCH, MCHC, and RDW), and serum ferritin were evaluated in all four groups of blood donors. The mean standard deviation of the hematological parameters is shown in (Table 3). A comparison of red cell indices and serum ferritin level between the groups showed the following results:

- Groups I and II: no significant difference was observed between with respect to red cell indices and serum ferritin.

- Groups I and III: a significant difference was observed with respect to $\mathrm{Hb}, \operatorname{Hct}(p=0.0347, p=0.0325)$, and serum ferritin level $(p=0.0032)$, but there was no significant difference between the groups with respect to other red cell indices. There was a $45 \%$ decrement in iron stores (mean serum ferritin) between the groups (Group 1 [101.57] and group III [56.69 $\mu \mathrm{g} / \mathrm{L}]$ ).

- Groups I and IV: all red cell indices of Group IV were significantly lower than those of Group I. There was a 
Table 1. Age-based distribution of donors according to the frequency of blood donation

\begin{tabular}{llcc}
\hline Groups (frequency of donations) & $\begin{array}{l}\text { Donors, } \\
n \text { (male:female) }\end{array}$ & Percentage, \% & $\begin{array}{l}\text { Age, years } \\
\text { (mean } \pm \text { SD) }\end{array}$ \\
\hline Group I (1-10) & $108(83: 25)$ & 29 & $29 \pm 8.40$ \\
Group II (11-20) & $101(90: 11)$ & 27 & $37 \pm 8.63$ \\
Group III (>21) & $100(98: 02)$ & 27 & $40 \pm 7.55$ \\
Group IV (regular donor deferred due to low Hb) & $65(38: 27)$ & 17 & $28 \pm 5.94$ \\
\hline Total & 374 & 100 & $33.5 \pm 7.63$ \\
\hline
\end{tabular}

Table 2. Mean serum ferritin level in the different age cohorts

\begin{tabular}{lcrrl}
\hline \multirow{2}{*}{$\begin{array}{l}\text { Age cohorts, } \\
\text { years }\end{array}$} & $\begin{array}{l}\text { Gender, } \\
\text { male:female }\end{array}$ & \multicolumn{2}{l}{ Serum ferritin, $\mu \mathrm{g} / \mathrm{L}$} & \multirow{2}{*}{$p$ value } \\
\cline { 3 - 4 } & males & females & \\
\hline $18-20$ & $29: 09$ & $68.8 \pm 35.65$ & $30.29 \pm 18.52$ & 0.029 \\
$21-30$ & $58: 30$ & $110.73 \pm 79.81$ & $37.99 \pm 26.70$ & 0.000 \\
$31-40$ & $126: 17$ & $74.92 \pm 73.21$ & $22.60 \pm 31.53$ & 0.000 \\
$41-50$ & $59: 09$ & $62.88 \pm 52.85$ & $54.31 \pm 35.38$ & 0.003 \\
$51-60$ & $37: 00$ & $59.79 \pm 28.15$ & - & - \\
\hline Total & $309: 65$ & $75.42 \pm 53.93$ & $36.29 \pm 28.03$ & 0.000 \\
\hline
\end{tabular}

Table 3. Hematological parameters in the different blood donor groups

\begin{tabular}{|c|c|c|c|c|c|c|c|}
\hline Groups & $\mathrm{Hb}, \mathrm{g} / \mathrm{dL}$ & Hct, \% & $\mathrm{MCV}, \mathrm{fL}$ & $\mathrm{MCHC}, \mathrm{g} / \mathrm{dL}$ & $\mathrm{MCH}, \mathrm{pg} / \mathrm{cell}$ & RDW & $\begin{array}{l}\text { Serum ferritin, } \\
\mu \mathrm{g} / \mathrm{L}\end{array}$ \\
\hline Group I & $14.71 \pm 1.47$ & $44.39 \pm 4.45$ & $87.13 \pm 5.39$ & $33.21 \pm 1.05$ & $28.99 \pm 2.33$ & $12.53 \pm 1.01$ & $101.57 \pm 66.51$ \\
\hline Group II & $14.61 \pm 1.05$ & $44.37 \pm 3.01$ & $88.23 \pm 4.87$ & $33.09 \pm 0.92$ & $29.26 \pm 1.98$ & $12.59 \pm 1.06$ & $73.97 \pm 135.42$ \\
\hline Group III & $14.36 \pm 1.36$ & $43.28 \pm 3.48$ & $87.90 \pm 7.81$ & $33.02 \pm 1.46$ & $29.09 \pm 3.30$ & $12.81 \pm 1.14$ & $56.69 \pm 40.45$ \\
\hline Group IV & $12.02 \pm 0.42$ & $37.36 \pm 1.40$ & $85.24 \pm 7.60$ & $31.64 \pm 1.35$ & $27.76 \pm 2.99$ & $13.25 \pm 1.38$ & $23.57 \pm 48.02$ \\
\hline $\begin{array}{l}\text { Inter-group } \\
\text { comparison } \\
\text { (with } \\
p<0.05 \text { ) }\end{array}$ & $\begin{array}{l}\text { Groups } 1 \text { and } 3 \\
(0.0347) \\
\text { Groups } 1 \text { and } 4 \\
(0.0001)\end{array}$ & $\begin{array}{l}\text { Groups } 1 \text { and } 3 \\
(0.0325) \\
\text { Groups } 1 \text { and } 4 \\
(0.0001)\end{array}$ & $\begin{array}{l}\text { Groups } 1 \text { and } 4 \\
(0.0236)\end{array}$ & $\begin{array}{l}\text { Groups } 1 \text { and } 4 \\
(0.0001)\end{array}$ & $\begin{array}{l}\text { Groups } 1 \text { and } 4 \\
(0.0004)\end{array}$ & $\begin{array}{l}\text { Groups } 1 \text { and } 4 \\
(0.0284)\end{array}$ & $\begin{array}{l}\text { Groups } 1 \text { and } 3 \\
(0.0032) \\
\text { Group } 1 \text { and } 4 \\
(0.0001)\end{array}$ \\
\hline
\end{tabular}

$78 \%$ decrement in iron stores (mean serum ferritin) between the groups.

- Groups II and III: the percentage of blood donors with reduced iron stores (ferritin 15-30 $\mu \mathrm{g} / \mathrm{L}$ ) increased with the number of donations (Table 4). Similarly, the percentage of blood donors with iron deficiency erythropoiesis increased with the number of donations. None of the group I, II, and III donors had $<15 \mu \mathrm{g} / \mathrm{L}$ with a microcytic/hypochromic picture in the hemogram. In the study, a population of around $37(9.8 \%)$ were in Stage 1 of reduced iron stores; 42 (11.2\%) were in iron deficiency erythropoiesis (Stage 2); and 18 $(4.8 \%)$ were in Stage 3, respectively (Table 5).

\section{Discussion}

Chronic iron deficiency is one of the most common observations seen in long-term regular blood donors [1, 9]. It was detected in regular donors with a donation frequency of more than three times a year, who were not compensated by iron absorption $[10,11]$. The blood bank should hold liability in protecting donors, which includes the prevention of anemia and also bringing awareness to iron supplementation and dietary modification. In the present study, we stratified the regular blood donors into different groups based on the number of donations and compared these with the body iron status. 
Table 4. Distribution of donors according to body iron stores and number of donations

\begin{tabular}{lllll}
\hline Groups & $\begin{array}{l}\text { Donors, } \\
n\end{array}$ & $\begin{array}{l}\text { Stage 1, } \\
\text { serum ferritin }<15-30 \mu \mathrm{g} / \mathrm{L} \\
\text { (reduced iron balance) }\end{array}$ & $\begin{array}{l}\text { Stage 2, } \\
\text { serum ferritin }<15 \mu \mathrm{g} / \mathrm{L} \\
\text { (iron deficiency erythropoiesis } \\
\text { with normal Hb) }\end{array}$ & $\begin{array}{l}\text { Stage 3, } \\
\text { serum ferritin }<15 \mu \mathrm{g} / \mathrm{L} \\
\text { (with features of anemia) }\end{array}$ \\
\hline Group I & 108 & $6(5.5 \%)$ & $4(3.7 \%)$ & 0 \\
Group II & 101 & $9(8.9 \%)$ & $8(7.9 \%)$ & 0 \\
Group III & 100 & $11(11 \%)$ & $12(12 \%)$ & 0 \\
Group IV & 65 & $11(17 \%)$ & $18(27.6 \%)$ & $18(27.6 \%)$ \\
\hline
\end{tabular}

We noted that the mean $\mathrm{Hb}$ and Hct values were significantly lower in Group III in comparison to Group I. However, we did not observe any correlation between the number of donations and the $\mathrm{MCV}$ and $\mathrm{MCH}$ values. $\mathrm{Al}-$ exander et al. [12] observed a significant negative correlation between the number of donations and Hb levels. In addition, they found an association between reduced $\mathrm{MCV}$ and $\mathrm{MCH}$ levels and an increasing frequency of blood donation.

In groups I, II and III, 9.2, 16.8, and 23\%, respectively, had reduced BIS. Iron depletion in the different groups increased along with the increase in the number of donations; i.e., by $5.5 \%$ in group I and $17 \%$ in group IV, and this finding is in accordance with the earlier studies mentioned in the literature $[3,10,15]$.

The mean ferritin values decreased in regular blood donors as early as after ten donations, implying that testing for serum ferritin should be done even at an earlier stage, preferably after five donations. This is to know the iron stores even before depletion. In this study, $83 \%$ of the female and $76 \%$ of the male donors with anemia $(\mathrm{Hb}$ $<12.5 \mathrm{~g} / \mathrm{dL}$ ) showed low ferritin values; i.e., $<20 \mu \mathrm{g} / \mathrm{L}$, which was similar to the findings of Alvarez et al. [15]. Thus, it provides clinical evidence for considering serum ferritin as part of routine screening and decision-making for the need of iron supplementation. The majority of male first-time donors in our study had lower ferritin levels; i.e., $68.8 \mu \mathrm{g} / \mathrm{L}$ compared to the western Indian counterparts, as shown in studies conducted by Javadzadeh Shahshahani et al. [14] (86.7 $\mu \mathrm{g} / \mathrm{L})$, Abdullah et al. [3] $(131.4 \mu \mathrm{g} / \mathrm{L})$, and Alvarez et al. [15] $(141 \mu \mathrm{g} / \mathrm{L})$, thus indicating the donors' vulnerability of developing anemia upon repeated donations.

Our study also had the limitation that serum ferritin is an acute-phase reactant. Therefore, it is elevated in inflammatory conditions. Donors are screened prior to donation for any potential ill effects, but the inclusion of C-reactive protein would still rule out an increase in serum ferritin due to any other cause. This would be useful for a better interpretation of the results. Though the sample size was surpassed in the study, researchers opine a bigger sample would give a better picture of the situation.
Table 5. Three stages of iron deficiency and blood donor distribution

\begin{tabular}{lc}
\hline Stages of iron deficiency & Donors, $n(\%)$ \\
\hline Stage 1: reduced iron & $37(9.8)$ \\
Stage 2: iron deficiency erythropoiesis & $42(11.2)$ \\
Stage 3: iron deficiency anemia & $18(4.8)$ \\
\hline Total & $97 / 374(25.9)$ \\
\hline
\end{tabular}

It would be better to decentralize the sample to all parts of the country to have a better picture of the iron status of the entire country. The inclusion of other biochemical markers such as soluble transferrin receptors, serum iron, and TIBC would also have been useful to better interpret the findings. The main concern was donors who had deficient stores but normal $\mathrm{Hb}$ count and on further donations would eventually progress to the stage of iron deficiency anemia. We have not considered the inter-donation intervals in the present study, and, to a certain extent, this could have influenced the results in the present study. Iron-deficient erythropoiesis was observed in $11.2 \%$ of the regular donors, and they are at risk for developing iron deficiency anemia. Further donations in these cases can compromise donor safety. As Group II donors had a 2.2 times higher risk of progressing to iron-deficient erythropoiesis stage, ferritin screening after the first donation and followed up at the tenth donation might help detect individuals at risk. Iron supplementation may be considered after donation in all donors with low ferritin level, regardless of $\mathrm{Hb}$ concentration.

\section{Statement of Ethics}

As per the hospital transfusion policy, informed consent was obtained from all individual participants included in the study. All procedures performed in studies involving human participants were in accordance with the ethical standards of the institutional ethics committee and with the 1964 Helsinki declaration and its later amendments or comparable ethical standards (IEC508/2015). 


\section{Disclosure Statement}

The authors declare that they have no conflicts of interest to disclose.

\section{Funding Sources}

The authors did not receive any funding.

\section{Author Contributions}

Dr. Shamee Shastry and Dr. Vijayram Reddy K contributed to the conceptualization, study design, and data acquisition. Dr. Manish Raturi contributed to data interpretation and drafting the paper. Dr. Poornima Baliga B helped in the critical revision of the draft.

\section{References}

1 Finch CA, Cook JD, Labbe RF, Culala M. Effect of blood donation on iron stores as evaluated by serum ferritin. Blood. 1977 Sep;50(3): 441-7.

2 Kiss JE, Birch RJ, Steele WR, Wright DJ, Cable RG. Quantification of body iron and iron absorption in the REDS-II Donor Iron Status Evaluation (RISE) study. Transfusion. 2017; 57(7):1656-64.

3 Abdullah SM. The effect of repeated blood donations on the iron status of male Saudi blood donors. Blood Transfus. 2011 Apr;9(2): $167-71$.

4 Vuk T, Magnussen K, De Kort W, Folléa G, Liumbruno GM, Schennach H, et al. International forum: an investigation of iron status in blood donors. Blood Transfus. 2017 Jan; 15(1):20-41.

5 Mast AE. Low hemoglobin deferral in blood donors. Transfus Med Rev. 2014 Jan;28(1): $18-22$.
6 Jeremiah ZA, Koate BB. Anaemia, iron deficiency and iron deficiency anaemia among blood donors in Port Harcourt, Nigeria. Blood Transfus. 2010 Apr;8(2):113-7.

7 Saran RK. Donors Selection and Blood Collection. In: Saran RK. Transfusion Medicine Technical Manual. DGHS. 2nd ed. 2003. p. 7-17.

8 National AIDS Control Organisation, Ministry of Health and Family Welfare, Government of India. Voluntary blood donation programme-An operational guideline. 2007;13. Available from: naco.gov.in/sites/default/ files/29\%2Cvoluntary blood donation.pdf.

9 Pedersen NS, Morling N. Iron stores in blood donors evaluated by serum ferritin. Scand J Haematol. 1978 Jan;20(1):70-6.

10 Jaime JC, Cazarez R, Mares MA, Marfil LJ, Harrison CR. Iron stores in remunerated blood donors as evaluated by plasma ferritin levels. Transfusion. 1988 Jan-Feb;28(1):62-5.
11 Garry PJ, VanderJagt DJ, Wayne SJ, Koehler KH, Rhyne RL, Simon TL. A prospective study of blood donations in healthy elderly persons. Transfusion. 1991 Oct;31(8):686-92.

12 Alexander HD, Sherlock JP, Bharucha C. Red cell indices as predictors of iron depletion in blood donors. Clin Lab Haematol. 2000 Oct; 22(5):253-8.

13 Greer JP, Foerster J, editors. Iron Deficiency and Related Disorders. In: Wintrobe's Clinical Hematology. Lippincott Williams \& Wilkins; 2003. p. 1946.

14 Javadzadeh Shahshahani H, Attar M, Taher Yavari M. A study of the prevalence of iron deficiency and its related factors in blood donors of Yazd, Iran, 2003. Transfus Med. 2005 Aug;15(4):287-93.

15 Alvarez-Ossorio L, Kirchner $\mathrm{H}$, Klüter $\mathrm{H}$, Schlenke P. Low ferritin levels indicate the need for iron supplementation: strategy to minimize iron-depletion in regular blood donors. Transfus Med. 2000 Jun;10(2):107-12. 